The Utilization of Spin Polarized Photoelectron Spectroscopy as a Probe of Electron Correlation with an Ultimate Goal of $\mathrm{Pu}$

J. G. Tobin, S. W. Yu, B. W. Chung, S. A. Morton,

T. Komesu, G. D. Waddill

February 11,2008

Symposium Proceedings of the Material Research Society 
This document was prepared as an account of work sponsored by an agency of the United States government. Neither the United States government nor Lawrence Livermore National Security, LLC, nor any of their employees makes any warranty, expressed or implied, or assumes any legal liability or responsibility for the accuracy, completeness, or usefulness of any information, apparatus, product, or process disclosed, or represents that its use would not infringe privately owned rights. Reference herein to any specific commercial product, process, or service by trade name, trademark, manufacturer, or otherwise does not necessarily constitute or imply its endorsement, recommendation, or favoring by the United States government or Lawrence Livermore National Security, LLC. The views and opinions of authors expressed herein do not necessarily state or reflect those of the United States government or Lawrence Livermore National Security, LLC, and shall not be used for advertising or product endorsement purposes. 
Spring 2008 Materials Research Society Meeting

Actinides IV, Symposium NN

San Francisco, CA, USA

March 24-28, 2008

\title{
The Utilization of Spin Polarized Photoelectron Spectroscopy as a Probe of Electron Correlation with an Ultimate Goal of Pu
}

\author{
J.G. Tobin ${ }^{1}$, S.W. Yu ${ }^{1}$, B.W. Chung ${ }^{1}$, S.A. Morton ${ }^{1,2}$, \\ T. Komesu ${ }^{3},{ }^{*}$ and G.D. Waddill ${ }^{3}$
}

\section{Lawrence Livermore National Laboratory, LLNS-LLC, Livermore, CA, USA \\ 2.Lawrence Berkeley National Laboratory, Berkeley, CA, USA 3.University of Missouri-Rolla, Department of Physics, Rolla, MO, USA}

We are developing the technique of spin-polarized photoelectron spectroscopy as a probe of electron correlation with the ultimate goal of resolving the Pu electronic structure controversy. Over the last several years, we have demonstrated the utility of spin polarized photoelectron spectroscopy for determining the fine details of the electronic structure in complex systems such as those shown below.

The proposed half-metallic ferro-magnet Fe3O4 [Figure 1, Ref 2]

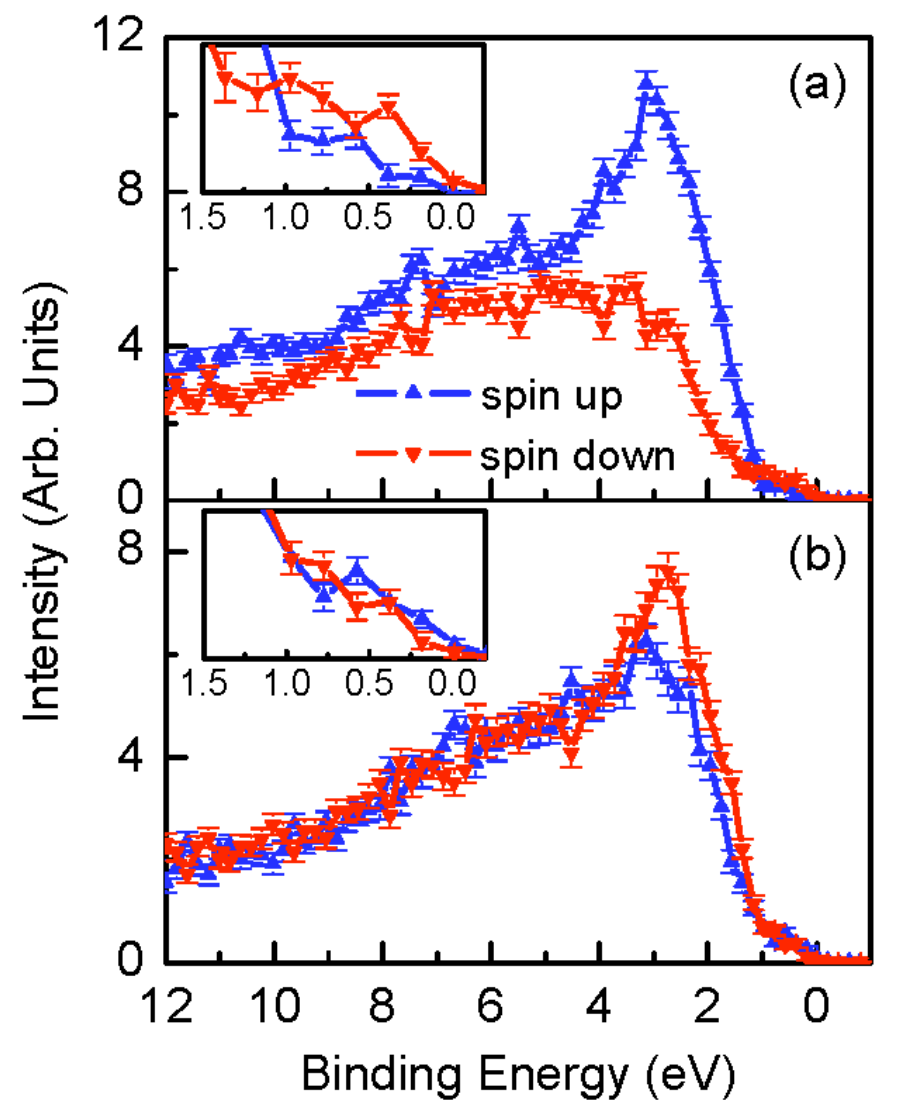

Figure 1

a) Spin resolved photoemission spectra from a) "as received" sample $\mathrm{h} v=160 \mathrm{eV}$.

b) Spin resolved photoemission spectra from a sample after $\mathrm{Ne}+$ sputtering, $\mathrm{h} v=160 \mathrm{eV}$.

Note the large effect observed in the as received sample in (a) and the reduction of the effect in (b) 
Spring 2008 Materials Research Society Meeting

Actinides IV, Symposium NN

San Francisco, CA, USA

March 24-28, 2008

The $2 p$ core levels of ultra-thin films such as Fe [Figure 2, Ref 3].

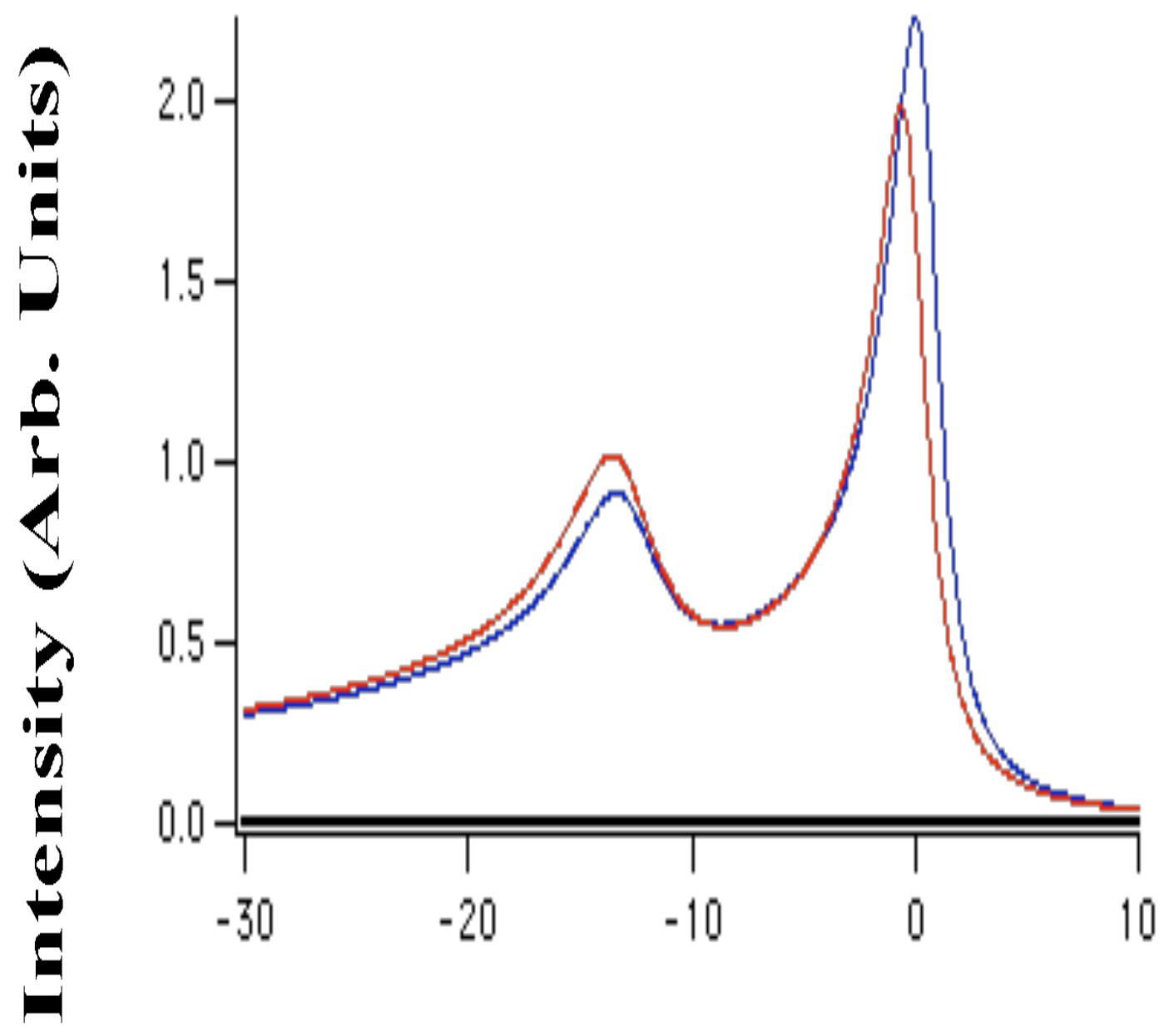

\section{Relative Binding Energy (eV)}

Figure 2

Simulated spin-resolved spectrum of the Fe $2 p$ doublet, following Reference 3. Red is spin up and blue is spin down. 
Spring 2008 Materials Research Society Meeting

Actinides IV, Symposium NN

San Francisco, CA, USA

March 24-28, 2008

The valence states of Fe on compound semiconductors [Figure 3, Ref 4].

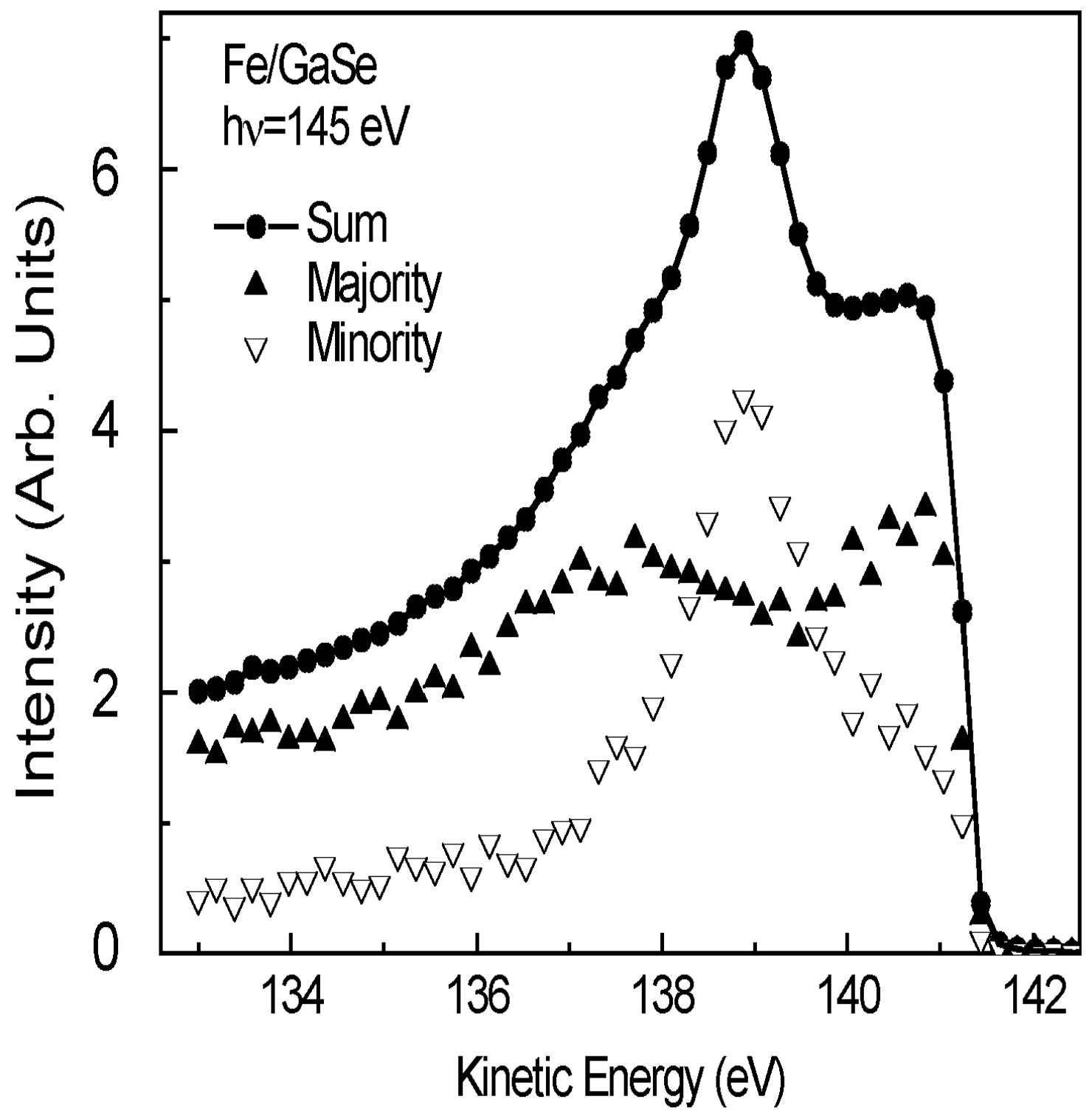

Figure 3

An example of some data collected on Beamline 7 at the ALS is shown here. The photon energy was $145 \mathrm{eV}$ and the photon polarization is linear. The spinresolved valence band photoemission results are from Fe overlayers, as part of a larger collaboration. [4] The Fermi edge is near $141 \mathrm{eV}$ Kinetic Energy. 
Spring 2008 Materials Research Society Meeting Actinides IV, Symposium NN

San Francisco, CA, USA

March 24-28, 2008

The non-magnetic system Ce [Figure 4, Ref 5-7].

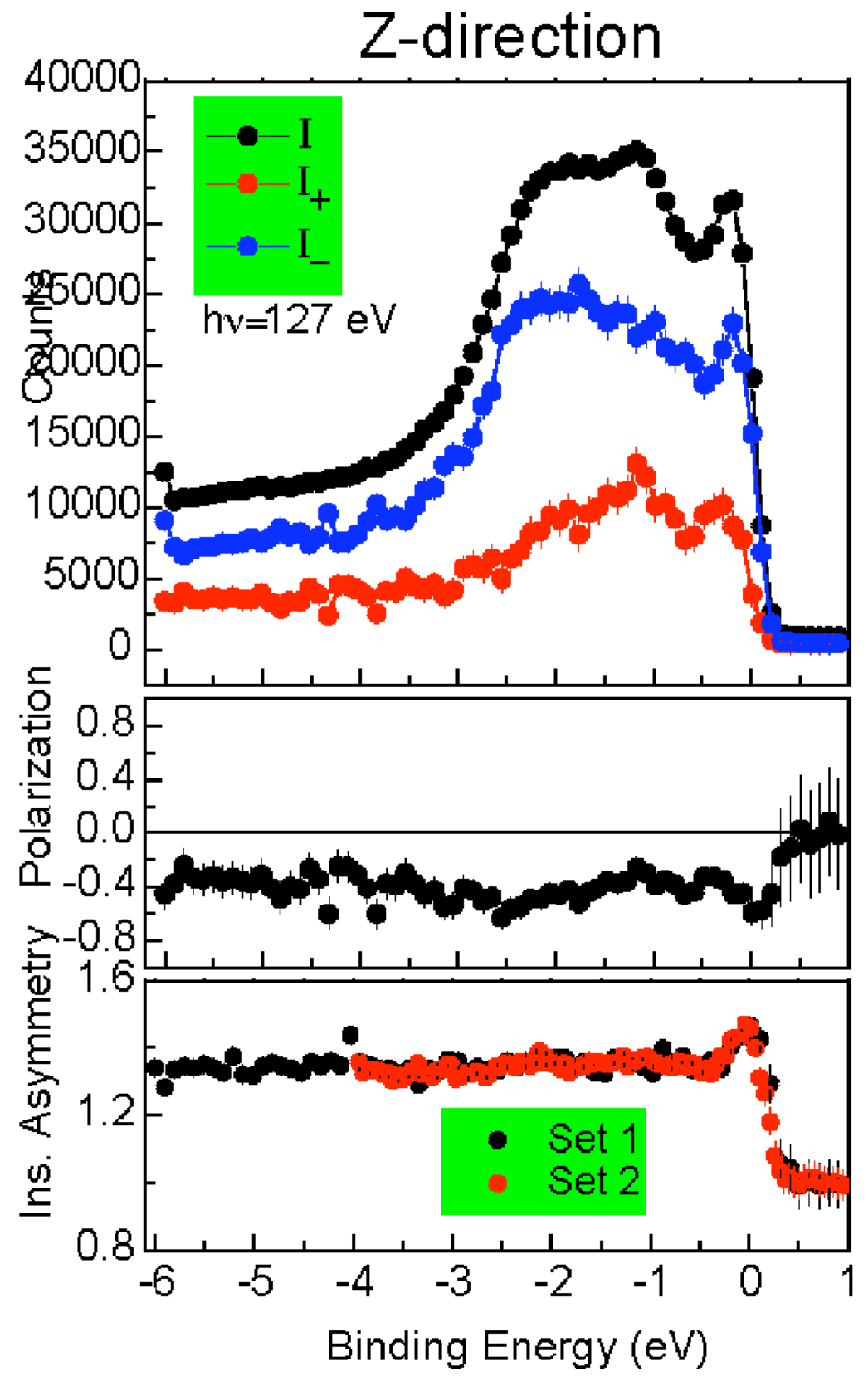

Figure 4

Spin resolved results for a polycrystalline film of Ce deposited upon W(110). The photon energy was $127 \mathrm{eV}$. Top panel: spin polarized spectra. Middle panel: polarization. Lowest panel: Instrumental asymmetry. Circularly polarized photons were used to generate the spin dependence. 
Spring 2008 Materials Research Society Meeting

Actinides IV, Symposium NN

San Francisco, CA, USA

March 24-28, 2008

The non-magnetic system Pt [Figure 5, Ref 8].
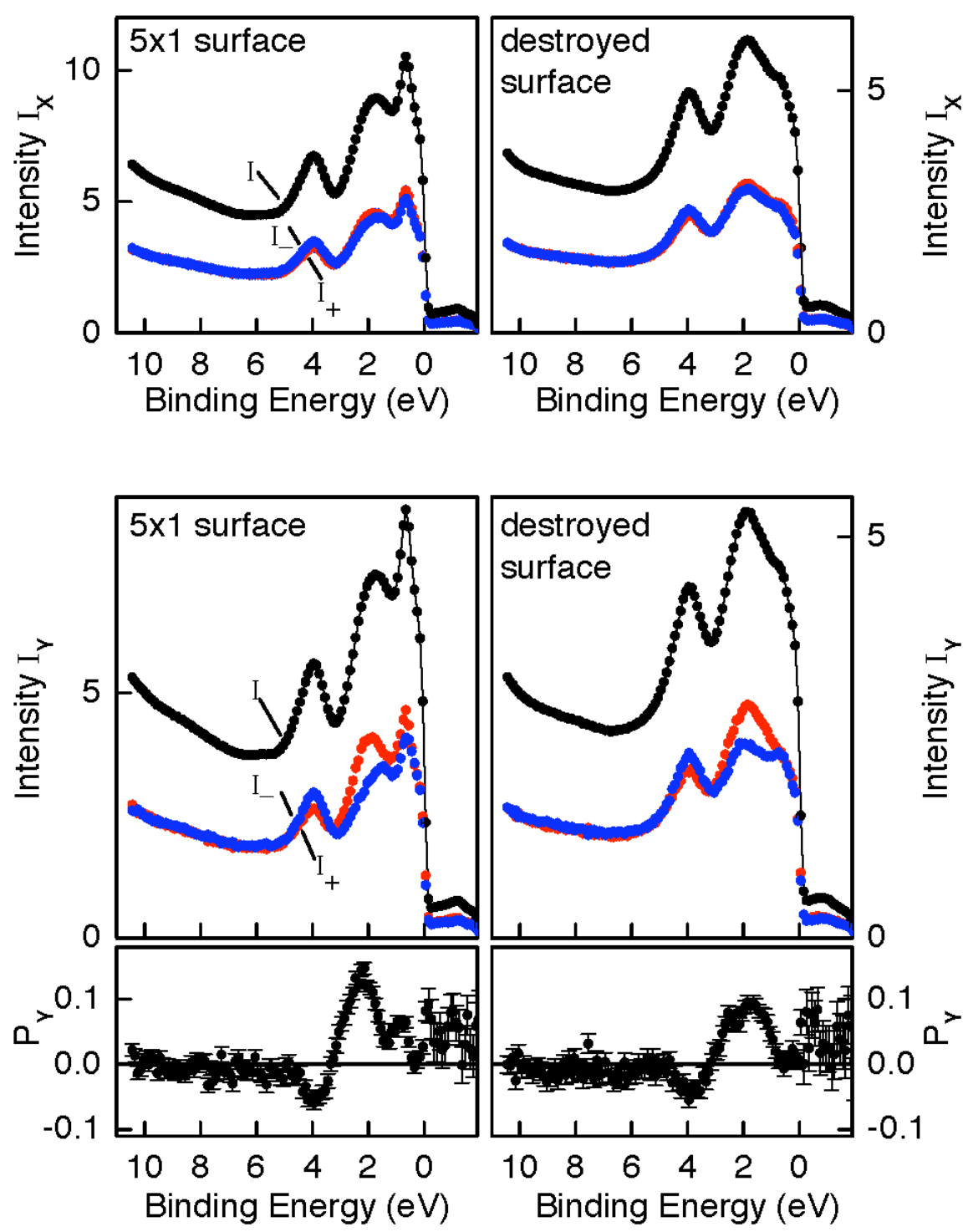

Figure 5

Spin-resolved photoemission spectra obtained with unpolarized $\mathrm{He} \mathrm{I}(\mathrm{h} v=21.2$ $\mathrm{eV}$ ) light for normal emission from the valence bands of Pt(001). Upper panel for $P_{X}$ component: The spin integrated total intensity I(black) and spin separated partial intensities $I^{+}$in red and $l_{i}$ in blue are shown for $5 \times 1$ surface and destroyed surface. Since the measured spin polarization $P_{X}$ is zero, the partial intensities I+ and $l_{i}$ are identical. Lower panel for $P_{Y}$ component: The spin integrated total intensity $l$ (black) and spin separated partial intensities $I+$ in red and $l_{i}$ in blue are shown for $5 \times 1$ surface and destroyed surface. The measured spin polarizations $P_{Y}$ for $5 \times 1$ surface and destroyed surface are shown. Note the loss of the $5 \times 1$ reconstructed surface state intensity at the binding energy of $0.66 \mathrm{eV}$ with the destruction of the surface order for both $X$ and $Y$ components. 
Spring 2008 Materials Research Society Meeting

Actinides IV, Symposium NN

San Francisco, CA, USA

March 24-28, 2008

Various recent publications have addressed the ongoing question of the nature of the Pu electronic structure. $[9,10]$ One possibility is the existence of a Kondo-like shielding of the $5 f$ electrons. [1] We propose that spin resolved PES is the most promising approach to resolving this question. [7,11]

Acknowledgements

Lawrence Livermore National Laboratory is operated by Lawrence Livermore National Security, LLC, for the U.S. Department of Energy, National Nuclear Security Administration under Contract DE-AC52-07NA27344. Work that was performed by UMR personnel was supported in part by the Office of Basic Energy Science at the U.S Department of Energy. Work that was performed by LLNL personnel was supported in part by the Office of Basic Energy Science at the U.S Department of Energy and Campaign 2 of $\mathrm{WCl}$ at LLNL.

- $\quad$ Present Address, Spring8 Synchrotron Radiation Facility, Japan

\section{References}

1. J.H. Shim, K. Haule and G. Kotliar, Nature 446, 513 (2007).

2. J.G. Tobin, S.A. Morton, S.W. Yu, G.D. Waddill, I.K. Schuller, and S.A. Chambers, J. Phys. Condens. Matter 19, 315218 (2007).

3. T. Komesu, G.D. Waddill, S.-W. Yu, M. Butterfield, and J.G. Tobin, "SpinOrbit Effects in Spin-Resolved $\mathrm{L}_{2,3}$ Core Level Photoemission of 3d Ferromagnetic Thin Films," under preparation; J.G. Tobin and F.O. Schumann, Surface Science 478, 211 (2001).

4. J.G. Tobin, S.A. Morton, S.W. Yu, T. Komesu, G.D. Waddill and P. Boyd, Nuclear Instrum. Methods A 582, 165 (2007); J. D. W. Thompson, J. R. Neal, T. H. Shen, S. A. Morton, J. G. Tobin, G. D. Waddill, J.A.D. Matthew, D. Greig, and M. Hopkinson, submitted to PRB, 2007.

5. S.W. Yu et al, Phys. Rev. B 73, 075116 (2006).

6. J.G. Tobin, S.A. Morton, B.W. Chung, S.W. Yu and G.D. Waddill, Physica B 378-380, 925 (2006).

7. J.G. Tobin, S.W. Yu, T. Komesu, B.W. Chung, S.A. Morton, and G.D. Waddill, Europhysics Lett., 77, 17004 (2007).

8. S.-W. Yu and J.G. Tobin, Surface Science Letters 601, L127 (2007).

9. J.G. Tobin et al, Phys. Rev. B 68, 155109 (2003).

10.J.G. Tobin et al, Phys. Rev. B 72, 085109 (2005).

11. J.G. Tobin, J. Alloys Cmpds 444-445, 154 (2007). 